\title{
Short-term outcomes of modified Y-graft technique in acute type a aortic dissection using the femoral artery bypass and one minute systemic circulatory arrest technique
}

Xiangfei Sun ${ }^{1,2}$, Qi Zhao ${ }^{3,4}$, Yufeng Huo ${ }^{5}$, Jinfeng Zhou ${ }^{5}$, Fen Zhao ${ }^{5}$, Yimin Liü ${ }^{5}$, Yonghai Du ${ }^{5}$, Songxiong He ${ }^{5}$, Chao Liu ${ }^{5}$, Detian Jiang ${ }^{5}$ and Wenyu Sun ${ }^{5^{*}}$

\begin{abstract}
Objective: Aortic arch replacement in acute type A aortic dissection patients remains the most challenging cardiovascular operation. Herein, we described our modified Y-graft technique using the Femoral Artery Bypass (FAB) and the One Minute Systemic Circulatory Arrest (OSCA) technique, and assessed the short-term outcomes of the patients.

Methods: Between February 2015 and November 2017, 51 patients with acute type A aortic dissection underwent aortic arch replacement. Among them, 23 patients underwent FAB while 28 patients underwent both FAB and OSCA. The intraoperative data and postoperative follow-up data were recorded. The follow-up data of patients with traditional Y-graft technique were collected from previously reported studies.

Results: In the FAB group, two patients died due to pulmonary infection (30-day survival rate, 91.3\%), and two patients were paralyzed from the waist down. Hemodialysis was performed for five patients (21.7\%) before hospital discharge. Fifteen patients (65.2\%) received respiratory support for more than 2-days and eight patients (34.8\%) for more than 5-days. These follow-up results were comparable or better than the patients with traditional Y-graft technique. Furthermore, compared to the FAB group, the morbidity due to neurological dysfunction and acute renal failure was significantly reduced in the FAB+OSCA group. Moreover, the respiratory support, length of postoperative stay and ICU stay were shortened.
\end{abstract}

Conclusions: This study clarified the feasibility of FAB and OSCA technique in modifying Y-graft technique. The acute type A aortic dissection patients showed less surgical complications and favorable short-term outcomes after this surgery.

Keywords: Modified Y-graft technique, Femoral artery bypass, One minute systemic circulatory arrest, Acute type a aortic dissection

\footnotetext{
* Correspondence: sdusunwenyu@sina.com

${ }^{5}$ Department of Cardiovascular Surgery, Qilu Hospital of Shandong University,

Qingdao 266011, Shandong, People's Republic of China

Full list of author information is available at the end of the article
}

(c) The Author(s). 2020 Open Access This article is licensed under a Creative Commons Attribution 4.0 International License, which permits use, sharing, adaptation, distribution and reproduction in any medium or format, as long as you give appropriate credit to the original author(s) and the source, provide a link to the Creative Commons licence, and indicate if changes were made. The images or other third party material in this article are included in the article's Creative Commons licence, unless indicated otherwise in a credit line to the material. If material is not included in the article's Creative Commons licence and your intended use is not permitted by statutory regulation or exceeds the permitted use, you will need to obtain permission directly from the copyright holder. To view a copy of this licence, visit http://creativecommons.org/licenses/by/4.0/ The Creative Commons Public Domain Dedication waiver (http://creativecommons.org/publicdomain/zero/1.0/) applies to the data made available in this article, unless otherwise stated in a credit line to the data. 


\section{Introduction}

The first successful aortic arch replacement was reported more than fifty years ago. With the development of the surgical technique and the improvement of patient care, the aortic arch can be repaired more safely now. However, total aortic arch replacement in acute type A aortic dissection patients remains the most challenging cardiovascular operation, which incurs high risk of cerebral damage and acute renal failure, and consequently, a considerable risk of operative mortality. The 30 -day mortality was as high as $18 \%$ and stroke rates were as high as $10 \%$ in 2011 [1].

In 2002, Spielvogel and colleagues developed the Ygraft technique to enable antegrade selective cerebral perfusion [2]. The individual reconstruction of brachiocephalic branches using a trifurcated graft benefitted the prognosis of the patients $[3,4]$. However, the outcome of the aortic arch replacement surgery is largely affected by the surgeon's skills and the tentative surgery techniques $[5,6]$. Hence, feasible and beneficial modifications of this technique are urgently needed.

Our team modified the traditional Y-graft technique using Femoral Artery Bypass (FAB) and One Minute Systemic Circulatory Arrest (OSCA) technique to simplify arch reconstruction, reduce embolization and avoid cerebral ischemia.

In the past 2 years, we have treated 51 cases of acute type A aortic dissection with our modified Y-graft technique for aortic arch replacement. The perioperative data and short-term follow-up data, such as perfusion time, 30-days survival rate, neurological dysfunction, length of respiratory support and acute renal failure, were recorded for all patients. The follow-up data of patients with traditional Y-graft technique were collected from previously reported studies. Herein, we described our modified Y-graft technique and assessed the shortterm outcomes of the patients.

\section{Patients and methods}

\section{Patients}

We conducted a retrospective analysis of the data from 51 patients who underwent aortic arch replacement between February 2015 and November 2017 at our hospital. The clinical features of the patients are shown in Table 1. Of these patients, 23 (45.1\%) underwent modified Y-graft technique using the FAB technique, and 28 (54.9\%) underwent modified Y-graft technique using the $\mathrm{FAB}+\mathrm{OSCA}$ techniques. The perioperative data and short-term follow-up data were recorded for all patients. Written informed consent was obtained from each patient. This study was approved by the Ethics Committee of Qilu Hospital of Shandong University.
Table 1 Patient characteristics

\begin{tabular}{ll}
\hline Characteristic & Value \\
\hline Number of patients & 51 \\
Age, years & $46.3 \pm 9.9$ \\
Sex, men: women & $42: 9$ \\
Emergency operation & $49(96.1 \%)$ \\
Marfan syndrome & $4(7.8 \%)$ \\
Aortic valve regurgitation & $18(35.3 \%)$ \\
Diabetes mellitus & $1(2.0 \%)$ \\
Smoking, past or current & $41(80.4 \%)$ \\
Hypertension & $48(94.1 \%)$ \\
Renal dysfunction & $3(5.9 \%)$ \\
Pulmonary disease & $1(2.0 \%)$ \\
Ischemic coronary heart disease & 4 \\
\hline
\end{tabular}

Data are reported as mean $\pm \mathrm{SD}$, median (interquartile range), or number (\%)

\section{Surgical technique}

The surgical procedure was divided into three stages.

\section{Stage 1: reconstruction of three branches (using FAB technique, Fig. 1)}

The femoral artery was exposed through a small incision in the inferior inguinal ligament. The left axillary artery was exposed through a small infra-clavicular incision. A median sternotomy was performed with extension of the incision superiorly along the medial border of the left sternocleidomastoid muscle and the brachiocephalic vessels were exposed.

Intravenous heparin was administered to achieve an activated clotting time $(\mathrm{ACT})>350 \mathrm{~s}$. A $10 \mathrm{~mm}$ graft ( $4 \mathrm{~cm}$ length) was end-to-side anastomosed to the femoral artery and then connected to the arterial tubes of the cardiopulmonary bypass (CPB) machine. Another $10 \mathrm{~mm}$ (15 cm length) graft was end-to-side anastomosed to the left subclavian artery and the other end of this graft was tunneled via the second intercostal space into the mediastinum on demand. The left common carotid artery was cannulated with an arterial catheter, which was connected to the arterial tubes of the CPB machine. Since the CPB machine did not work, the femoral artery-to-left common carotid artery bypass was completed. Then the left common carotid artery was transected. Another $8 \mathrm{~mm}$ graft was end-to-end anastomosed to the left common carotid artery. The previous $10 \mathrm{~mm}$ graft (connected to the left subclavian artery) was measured to the appropriate length and side-to-side anastomosed to this $8 \mathrm{~mm}$ graft (connected to the left common carotid artery). The free-end of the previous $10 \mathrm{~mm}$ graft (connected to the left subclavian artery) was tightly connected to the arterial tubes of the $\mathrm{CPB}$ machine. The free-end of the $8 \mathrm{~mm}$ graft (connected 


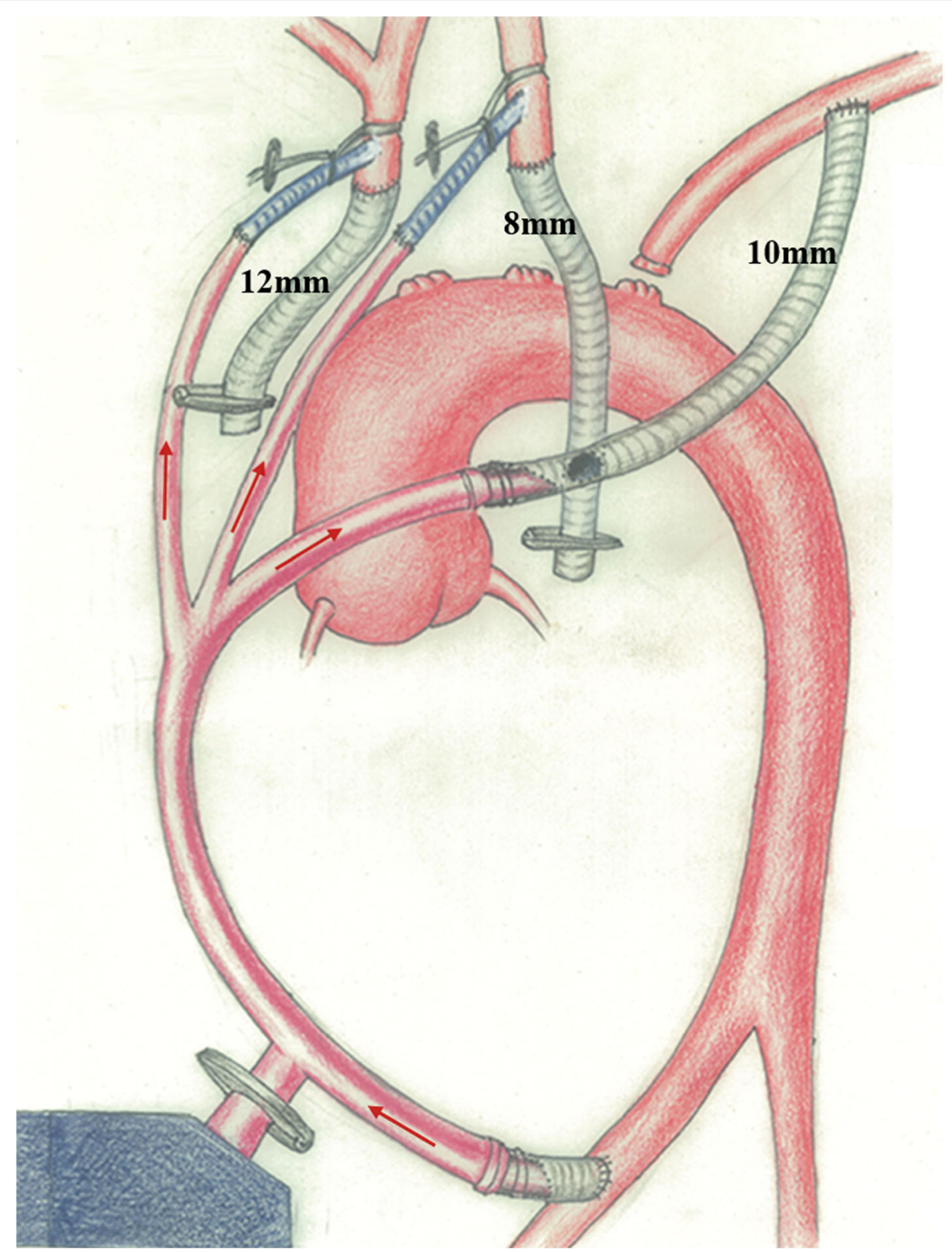

Fig. 1 Reconstruction of three branches using femoral artery bypass (FAB) technique. The construction of three bypasses: femoral artery-to-left common carotid artery bypass, femoral artery-to-left subclavian artery bypass and femoral artery-to-innominate artery bypass

to the left common carotid artery) was clamped. This is how both femoral artery-to-left common carotid artery bypass and the femoral artery-to-left subclavian artery bypass were completed. As for the innominate artery, the procedures of cannulation and anastomosis were similar to the left common carotid artery. The innominate artery was cannulated with an arterial catheter, which was connected to the arterial tubes of the $\mathrm{CPB}$ machine. A femoral artery-to-innominate artery bypass was completed. Then the innominate artery was transected. A $12 \mathrm{~mm}$ graft was end-to-end anastomosed to the innominate artery. The free-end of the $12 \mathrm{~mm}$ graft was clamped.

Finally, without the assistance of CPB machine, femoral artery-to-left common carotid artery bypass, femoral artery-to-left subclavian artery bypass and femoral artery-to-innominate artery bypass were all completed at room temperature, with continuous selective bilateral cerebral perfusion. The reconstruction of the three branches was also successfully completed. Every graft was carefully de-aired, and perfusion was restored to the head and upper extremities (Fig. 1). 


\section{Stage 2: reconstruction of the proximal aortic root}

The pericardium was opened after cannulation of the superior and inferior vena cava, and ensuring that the CPB machine worked and cooling was started. The ascending aorta was cross-clamped at $32{ }^{\circ} \mathrm{C}$ and the cardioplegic solution was usually perfused through a coronary sinus cannulation to arrest the heart. After the cardioplegic cardiac arrest, the aortic valve repair or replacement (Bentall) was performed if significant aortic valve insufficiency was identified through TEE. The ascending aorta was also replaced by the graft, which was anastomosed to the aortic sinotubular junction or the artificial valve ring.

\section{Stage 3: reconstruction of the aortic arch (using OSCA technique, Fig. 2)}

The completion of the reconstruction of the proximal aortic root usually coincided with the end of core cooling (target temperature: $32^{\circ} \mathrm{C}$ ). At the beginning of this stage, the patient was placed in slight Trendelenburg position, and the head was packed in ice. The cross-clamp was moved to the distal aortic arch (between the innominate artery and the left common carotid artery), and the aortic arch was trimmed. Hypothermic circulatory arrest was started after removing the clamp. The intraoperative stent (Stented Graft System In Surgical Operation) was placed into the distal aortic arch and then the aortic arch was immediately cross-clamped after de-airing (Fig. 2a). Thereafter, the lower-body perfusion was restored, and active rewarming was started. The duration of the hypothermic circulatory arrest was about $1 \mathrm{~min}$. The subsequent steps could be performed in an unhurried fashion. The proximal self-aortic arch and the intraoperative stent's graft section were trimmed, and the sandwich treatment was performed (Fig. 2b). The previously placed graft on the root was retracted, stretched and measured to the site of distal anastomosis. Graft-to-graft anastomoses were performed. Then the aortic cross-clamp was removed.

Before the cannulation of the innominate artery and removal of the graft connected to the left subclavian artery, the $8 \mathrm{~mm}$ graft (left common carotid artery) was end-to-side anastomosed to the $12 \mathrm{~mm}$ graft (innominate artery). The free-end of the $12 \mathrm{~mm}$ graft (innominate artery) was end-to-side anastomosed to the ascending graft in ideal site (Fig. 2c). Antegrade bilateral cerebral and upper extremity perfusion was not interrupted in these three stages. On completion of this final anastomosis, active rewarming continued until the patient could be weaned from $\mathrm{CPB}$.

\section{Variables and statistical analysis}

Patients were followed-up by cardiologists. Telephone interview of patients was performed. The follow-up period was 30 days after operation. We defined operative mortality as death within 30 days of operation. Neurological dysfunction was defined as any new clinically or radiographically evident brain injury present after the operation, especially the temporary or permanent paresis or paralysis that resolved before hospital discharge. Acute renal failure was defined as the need to initiate renal support with hemofiltration. Statistical analysis was performed using statistical software SPSS 16.0 for Windows 7. When the quantitative variables obeyed normal distribution, they were presented as mean $\pm S D$ and analyzed by the t-test. Skewed quantitative variables were presented as median and interquartile range, and analyzed by the rank-sum test. Univariate analysis of operative mortality, acute renal failure, neurological dysfunction and respiratory support was performed by the $\mathrm{X}^{2}$ test.
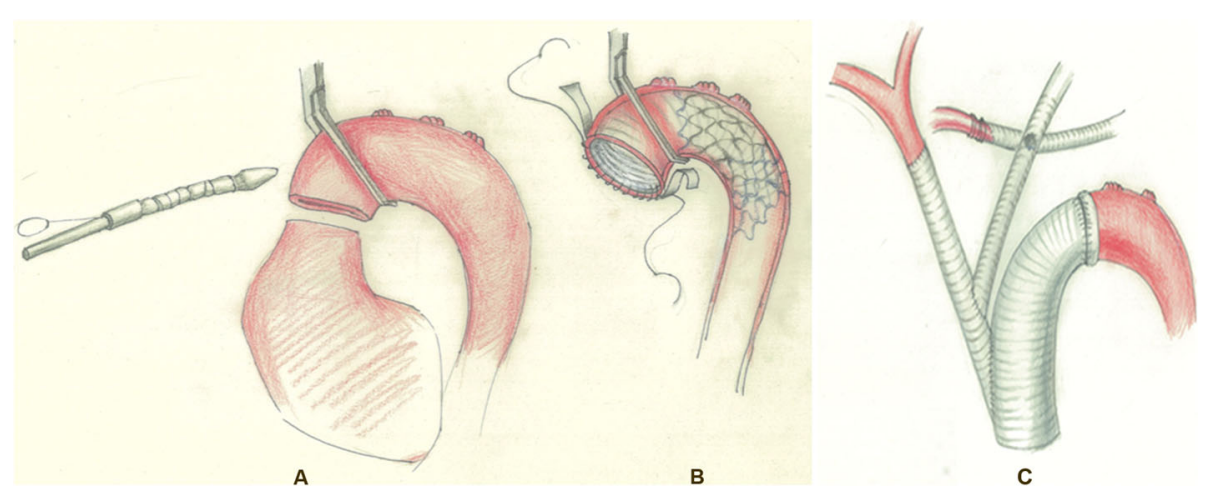

Fig. 2 One minute systemic circulatory arrest (OSCA) during the surgery. a The intraoperative stent was placed into the distal aortic arch. $\mathbf{b}$ The aortic arch was immediately cross-clamped after de-airing, which greatly shortened the duration of the hypothermic circulatory arrest to about 1 min. c The $8 \mathrm{~mm}$ graft was end-to-side anastomosed to the $12 \mathrm{~mm}$ graft (innominate artery). The free-end of the $12 \mathrm{~mm}$ graft was end-to-side anastomosed to the ascending graft in ideal site 


\section{Results}

The modified Y-graft technique using FAB has advantages in shortening the systemic circulatory arrest time and aortic clamp time, and its short-term outcomes are comparable or superior to the traditional Y-graft technique

Twenty-three acute type A aortic dissection patients underwent modified Y-graft technique using FAB. The operative and postoperative data indicating short-term outcomes, including the $\mathrm{CPB}$ time, systemic circulatory arrest time, aortic clamp time, cerebral circulatory arrest time, the skin-to-skin time, etc., were collected (Table 2).

Among the 23 patients who underwent FAB technique, two died within 30 -days $(8.7 \%)$, due to pulmonary infection. Two patients were paralyzed from the waist down, one of them was transient, while the other did not recover during the follow-up period. Hemodialysis was performed for five patients (21.7\%) during the follow-up period. Fifteen patients (65.2\%) received respiratory support for more than 2-days and eight patients $(34.8 \%)$ for more than 5-days. As for the traditional Y-graft technique, we reviewed previous articles and obtained the corresponding data (shown in Table 2). The results showed that the follow-up data in the patients using FAB modified Y-graft technique were comparable or superior to the data in patients with traditional Y-graft technique. The systemic circulatory arrest time and aortic clamp time were significantly shorter in the FAB modified group.

When using FAB in this surgery, the right brachiocephalic and left common carotid arteries can be reconstructed without $\mathrm{CPB}$ and cross-clamping the aorta, so the systemic circulatory arrest time and aortic clamp time are considerably shortened. Besides, all these procedures were performed at room temperature. Compared with the traditional Y-graft technique, the supra-aortic branches can be safely reconstructed in an unhurried fashion, especially if the surgeon is inexperienced. It was easy to repair a leak immediately after anastomoses of the supra-aortic arteries because of optimal mobility and slight wall tension of the anastomoses.

\section{Perioperative variables and short-term outcomes are}

\section{superior in modified Y-graft technique using FAB and OSCA}

Perioperative demographics of the patients, such as age (46.1 \pm 8.3 years), male gender (78.6\%), weight $(80.8 \pm 12.6$ $\mathrm{Kg})$, Marfan syndrome (7.1\%), aortic valve regurgitation (28.6\%), smoking, past or current (75.0\%), hypertension (92.9\%), renal dysfunction (7.1\%), and pulmonary disease, are shown in Table 3.

The operative variables are also shown in Table 3, including the median CPB time (204 min), the mean systemic circulatory time $(1.6 \mathrm{~min})$, the aortic clamp time $(92.9 \mathrm{~min})$, the cerebral circulatory time $(0 \mathrm{~min})$, the skin-to-skin time (432 $\mathrm{min})$, and the lowest nasopharyngeal temperature $\left(32{ }^{\circ} \mathrm{C}\right)$. Concomitant procedures included aortic valve replacement $(10.7 \%)$ and coronary artery bypass grafting (3.6\%).

The operative mortality was $7.1 \%$, and neurological dysfunction was $3.6 \%$. Among the 28 patients, 10 patients $(35.7 \%)$ had $>2$ days intubation and three patients $(10.7 \%)$ had $>5$ days intubation. Only one patient $(3.6 \%)$ had postoperative renal dysfunction and required temporary hemodialysis before discharge.

Comparison between the modified Y-graft technique using $F A B$ and modified Y-graft technique using FAB and OSCA

Comparison of these two groups is shown in Table 3. There were no significant differences in preoperative patient characteristics. Compared with the 23 patients who underwent modified Y-graft technique using FAB procedures, the 28 patients who underwent modified Y-graft technique using $\mathrm{FAB}+\mathrm{OSCA}$ had shorter $\mathrm{CPB}$ time (Fig. 3a), systemic circulatory arrest time (Fig. 3b), aortic clamp time (Fig. 3c), and higher lowest nasopharyngeal temperature $\left(32^{\circ} \mathrm{C}\right)$. The percentage of the concomitant aortic valve replacement was also lower in the patients using $\mathrm{FAB}+\mathrm{OSCA}$ techniques (Fig. 3d). All these differences were statistically significant $(p<0.05)$, except for the aortic clamp time and the skin-to-skin time. As for the short-term outcomes, the 28 patients who underwent modified Y-graft technique using $\mathrm{FAB}+\mathrm{OSCA}$ had an operative mortality of $7.1 \%$ and the morbidity of neurological dysfunction was $3.6 \%$ (Fig. $4 \mathrm{~b}$ ). These data were statistically equal to the patients who underwent FAB alone. Furthermore, the FAB+OSCA patients had significantly shorter respiratory support duration (Fig. 4a) and lower morbidity due to acute renal failure ( $p<0.05$, Fig. $4 \mathrm{~b})$.

\section{Discussion}

Aortic arch replacement is one of the most technically challenging cardiovascular operations, incurring considerable risk for perioperative death, stroke, acute renal failure, etc. With the development of the aortic arch replacement surgery, Sun's procedure has become very popular in China. However, we reviewed numerous articles on Y-graft technique and learnt the operation at the Hartford Cardiovascular Center for 1 year. The Y-graft technique, in which a double Y-graft is used to connect brachiocephalic branches to the main aortic graft, was developed to accomplish arch reconstruction, reduce embolization, and minimize related cerebral ischemia. Recently, we treated 51 cases of acute type A aortic dissection with aortic arch replacement. We modified the procedure of the Y-graft technique and reduced the systemic circulatory arrest time to about a minute.

Originally, we modified the Y-graft technique using the femoral artery bypass (FAB). By this technique, we 
Table 2 Traditional Y-Graft techniques vs Modified Y-Graft techniques utilizing Femoral artery bypass (FAB)

\begin{tabular}{|c|c|c|}
\hline Variates & Traditional Y-Graft techniques & $\begin{array}{l}\text { Modified Y-Graft techniques utilizing } \\
\text { Femoral artery bypass }(n=23)\end{array}$ \\
\hline \multicolumn{3}{|l|}{ Operative variables } \\
\hline \multicolumn{3}{|l|}{ Perfusion and ischemic times, minutes } \\
\hline \multirow[t]{5}{*}{ Cardiopulmonary bypass } & $141(118-183)[1]$ & \multirow[t]{5}{*}{$236(200-290)$} \\
\hline & $236.2 \pm 52.5[7]$ & \\
\hline & $239 \pm 53.1[8]$ & \\
\hline & $279 \pm 82[9]$ & \\
\hline & $273 \pm 79[10]$ & \\
\hline \multirow[t]{4}{*}{ Systemic circulatory arrest } & $65(51-84)[1]$ & \multirow[t]{4}{*}{$20.6 \pm 6.9$} \\
\hline & $31.2 \pm 6.6[7]$ & \\
\hline & $78 \pm 34[9]$ & \\
\hline & $69 \pm 22[10]$ & \\
\hline \multirow[t]{3}{*}{ Aortic clamp } & $53.9 \pm 41.1[1]$ & \multirow[t]{3}{*}{$105 \pm 25.7$} \\
\hline & $144 \pm 55[9]$ & \\
\hline & $163 \pm 54[10]$ & \\
\hline Cerebral circulatory arrest & 0 & 0 \\
\hline \multirow{6}{*}{$\begin{array}{l}\text { Lowest nasopharyngeal/rectal } \\
\text { temperature, }{ }^{\circ} \mathrm{C}\end{array}$} & $22.0^{\circ} \mathrm{C}(19.1-23.7)[1]$ & \multirow[t]{6}{*}{$28^{\circ} \mathrm{C}$} \\
\hline & $12.8 \pm 2.2^{\circ} \mathrm{C}(9.9-19.8)[7]$ & \\
\hline & $15.8 \pm 2.1^{\circ} \mathrm{C}(12.0-22.1)[8]$ & \\
\hline & $24.0 \pm 2.2^{\circ} \mathrm{C}[9]$ & \\
\hline & $16-20^{\circ} \mathrm{C}[11]$ & \\
\hline & $23^{\circ} \mathrm{C}[10]$ & \\
\hline \multirow[t]{2}{*}{ Concomitant aortic valve replacement } & $40 \%[1]$ & \multirow[t]{2}{*}{$(n=8) 34.8 \%$} \\
\hline & $2.8 \%[7]$ & \\
\hline \multirow[t]{2}{*}{ Concomitant coronary artery bypass } & $9 \%[1]$ & \multirow[t]{2}{*}{$(n=3) 13.0 \%$} \\
\hline & $2.8 \%[7]$ & \\
\hline \multicolumn{3}{|l|}{ Outcomes } \\
\hline \multirow[t]{8}{*}{ Operative mortality } & $2 \%[1]$ & \multirow[t]{8}{*}{$(n=2) 8.7 \%$} \\
\hline & $4.6 \%[7]$ & \\
\hline & $4.7 \%[8]$ & \\
\hline & $4.9 \%[9]$ & \\
\hline & $6.8 \%[12]$ & \\
\hline & $2 \%[13]$ & \\
\hline & $6.8 \%[11]$ & \\
\hline & $6.8 \%[10]$ & \\
\hline \multirow[t]{6}{*}{ Neurologic dysfunction } & $5 \%[1]$ & \multirow[t]{6}{*}{$(n=3) 13.0 \%$} \\
\hline & $9.4 \%[8]$ & \\
\hline & $9.8 \%[9]$ & \\
\hline & $14 \%[14]$ & \\
\hline & $5 \%[13]$ & \\
\hline & $9.1 \%[11]$ & \\
\hline \multirow[t]{2}{*}{ Respiratory support } & $>2$ days $20-51 \%$ [10] & $>2$ days $(n=15) 65.2 \%$ \\
\hline & $>5$ days $5-30 \%$ [10] & $>5$ days $(n=8) 34.8 \%$ \\
\hline
\end{tabular}


Table 2 Traditional Y-Graft techniques vs Modified Y-Graft techniques utilizing Femoral artery bypass (FAB) (Continued)

\begin{tabular}{lll}
\hline Variates & Traditional Y-Graft techniques & $\begin{array}{l}\text { Modified Y-Graft techniques utilizing } \\
\text { Femoral artery bypass }(n=23)\end{array}$ \\
\hline Acute renal failure & $11 \%[1]$ & $(n=5) 21.7 \%$ \\
& $3.7 \%[7]$ & $6 \%[8]$ \\
$13.1 \%[9]$ & $5.4 \%[11]$ & \\
\hline
\end{tabular}

Data are reported as mean $\pm \mathrm{SD}$, median (interquartile range), or number (\%). The superscript numbers are the sequence number of references

can reconstruct the brachiocephalic branches at room temperature, without cardiopulmonary bypass (CPB). Even the pericardium does not need to be opened. The left subclavian artery is difficult to expose and anastomose. Nerve injury, especially recurrent laryngeal nerve, can easily occur. Notably, reconstruction of brachiocephalic branches is easier to perform by our modified technique. Besides, it is easy to repair a leak immediately after anastomoses of the supra-aortic arteries because of optimal mobility and slight wall tension of the anastomoses. Twenty-three patients underwent this modified technique. Subsequently, we modified the Y-graft technique using FAB and One Minute Systemic Circulatory Arrest (OSCA) technique. The latter technique majorly

Table 3 One minute systemic circulation arrest (OSCA)

\begin{tabular}{|c|c|c|c|}
\hline Variates & $\begin{array}{l}\text { Modified Y-Graft techniques utilizing Femoral } \\
\text { artery bypass (without OSCA, } n=23 \text { ) }\end{array}$ & $\begin{array}{l}\text { Modified Y-Graft techniques utilizing Femoral } \\
\text { artery bypass (with OSCA, } n=28 \text { ) }\end{array}$ & $P$ value \\
\hline \multicolumn{4}{|l|}{ Preoperative characteristics } \\
\hline Age, years & $46.5 \pm 11.8$ & $46.1 \pm 8.3$ & $P>0.05$ \\
\hline Male sex & $(n=20) 87.0 \%$ & $(n=22) 78.6 \%$ & $P>0.05$ \\
\hline Weight, Kg & $80.5 \pm 13.4$ & $80.8 \pm 12.6$ & $P>0.05$ \\
\hline Marfan syndrome & $(n=2) 8.7 \%$ & $(n=2) 7.1 \%$ & $P>0.05$ \\
\hline Aortic valve regurgitation & $(n=10) 43.5 \%$ & $(n=8) 28.6 \%$ & $P>0.05$ \\
\hline Diabetes mellitus & $(n=1) 4.3 \%$ & $(n=0) 0 \%$ & $P>0.05$ \\
\hline Smoking, past or current & $(n=20) 87.0 \%$ & $(n=21) 75.0 \%$ & $P>0.05$ \\
\hline Hypertension & $(n=22) 95.7 \%$ & $(n=26) 92.9 \%$ & $P>0.05$ \\
\hline Renal dysfunction & $(n=1) 4.3 \%$ & $(n=2) 7.1 \%$ & $P>0.05$ \\
\hline Pulmonary disease & $(n=1) 4.3 \%$ & $(n=0) 0 \%$ & $P>0.05$ \\
\hline \multicolumn{4}{|l|}{ Operative variables } \\
\hline \multicolumn{4}{|l|}{ Perfusion and ischemic times, minutes } \\
\hline Cardiopulmonary bypass & $236(200-290)$ & $204(169-246)$ & $P<0.05$ \\
\hline Systemic circulatory arrest & $20.6 \pm 6.9$ & $1.6 \pm 1.1$ & $P<0.05$ \\
\hline Aortic clamp & $105 \pm 25.7$ & $92.9 \pm 35.2$ & $P>0.05$ \\
\hline Cerebral circulatory arrest & 0 & 0 & NA \\
\hline Skin-to-skin time & $486 \pm 51.3$ & $432 \pm 40.5$ & $P>0.05$ \\
\hline Lowest nasopharyngeal temperature, ${ }^{\circ} \mathrm{C}$ & 28 & 32 & NA \\
\hline Concomitant aortic valve replacement & $(n=8) 34.8 \%$ & $(n=3) 10.7 \%$ & $P<0.05$ \\
\hline Concomitant coronary artery bypass & $(n=3) 13.0 \%$ & $(n=1) 3.6 \%$ & $P>0.05$ \\
\hline \multicolumn{4}{|l|}{ Outcomes } \\
\hline Operative mortality & $(n=2) 8.7 \%$ & $(n=2) 7.1 \%$ & $P>0.05$ \\
\hline neurologic dysfunction & $(n=3) 13.0 \%$ & $(n=1) 3.6 \%$ & $P>0.05$ \\
\hline \multirow[t]{2}{*}{ Respiratory support } & $>2$ days $(n=15) 65.2 \%$ & $>2$ days $(n=10) 35.7 \%$ & $P<0.05$ \\
\hline & $>5$ days $(n=8) 34.8 \%$ & $>5$ days $(n=3) 10.7 \%$ & $P<0.05$ \\
\hline Acute renal failure & $(n=5) 21.7 \%$ & $(n=1) 3.6 \%$ & $P<0.05$ \\
\hline
\end{tabular}

$N A$ not available. Data are reported as mean $\pm \mathrm{SD}$, median (interquartile range), or number (\%) 


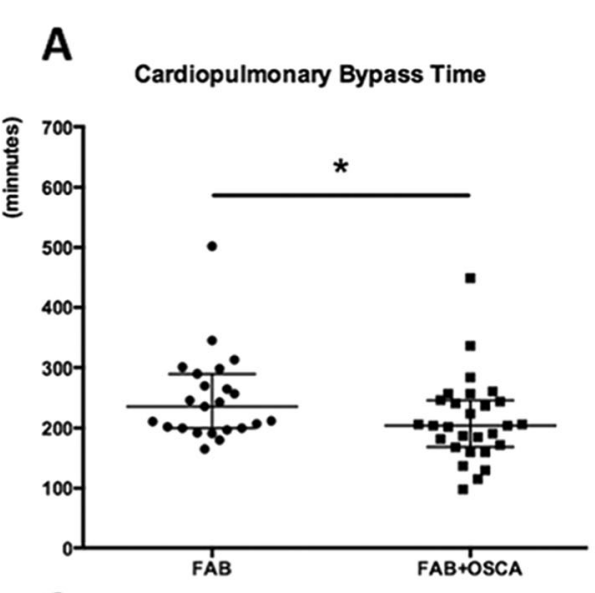

B Systemic Circulatory Arrest Time

C

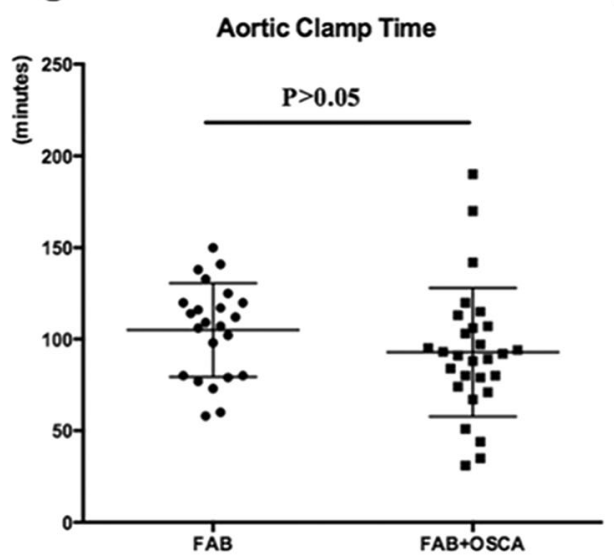

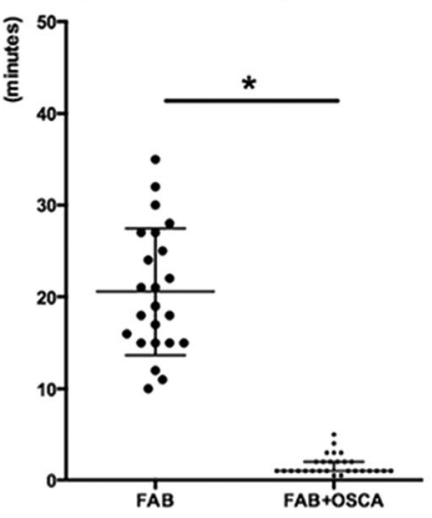

D

\section{Concomitant aortic valve replacement}

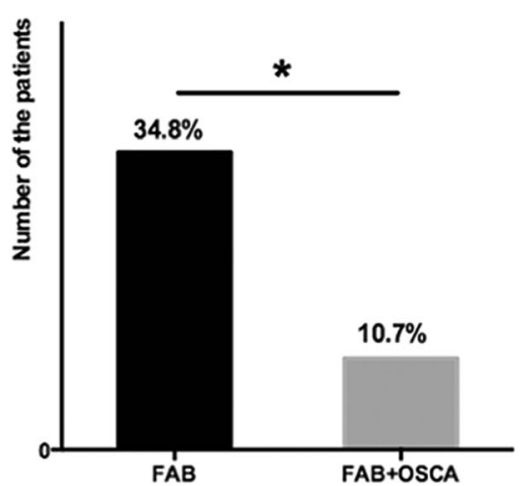

Fig. 3 Comparison of the operative variables between the modified Y-graft technique using FAB and modified Y-graft technique using FAB and OSCA. a, b The cardiopulmonary bypass time [236 (200-290) min, 204 (169-246) $\left.\mathrm{min},{ }^{*} p<0.05\right]$ and systemic circulatory arrest time (20.6 \pm 6.9 min, $\left.1.6 \pm 1.1 \mathrm{~min},{ }^{*} p<0.05\right)$ were significantly shortened after modified Y-graft technique using FAB+OSCA technique. $\mathbf{c}$ The aortic clamp time had no significant difference between the two groups (105 $\pm 25.7 \mathrm{~min}, 92.9 \pm 35.2 \mathrm{~min}, p>0.05)$. d The percentage of concomitant aortic valve replacement was lower in the patients with FAB+OSCA techniques $(34.8,10.7 \%, p<0.05)$. The error bars in A-C represent mean \pm Std. deviation. ${ }^{*} p<0.05, \mathrm{t}$-test
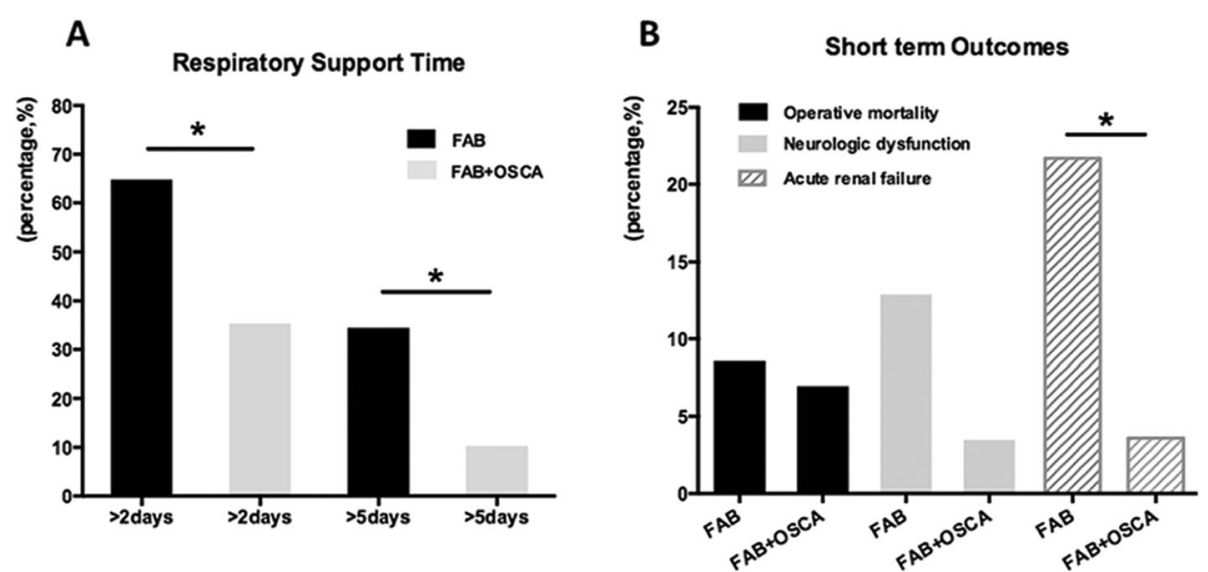

Fig. 4 Comparison of the outcomes between the modified Y-graft technique using FAB and modified Y-graft technique using FAB and OSCA. The 28 patients who underwent modified Y-graft technique using FAB+OSCA had an operative mortality of 7.1\% and the morbidity of neurological dysfunction was $3.6 \%(\mathbf{b})$, and these data were statistically equal to the patients who underwent only FAB. Furthermore, the FAB+OSCA patients had significantly shorter respiratory support duration (a) and lower morbidity due to acute renal failure (b). ${ }^{*} p<0.05$, chi-square test 
decreases the systemic circulatory arrest time, thus reducing the ischemic time of spinal cord and kidneys. Moreover, the lowest nasopharyngeal/rectal temperature can be maintained at $32{ }^{\circ} \mathrm{C}$. To summarize, our modified technique almost eliminated the systemic circulatory arrest time, and reduced the $\mathrm{CPB}$ time and other operative variables.

Comparison of the traditional Y-graft technique with the modified Y-graft technique using FAB (Table 2) showed that some of the indicators were not significantly advanced, but our FAB technique makes the operation easier than before. The reconstruction of the supra-aortic arteries can be accomplished in an unhurried fashion and the quality of anastomosis can be improved. It also provides a good surgical visual field for distal aortic anastomosis and eases the blood leak sealing.

Comparison of the $\mathrm{FAB}$ technique and $\mathrm{FAB}+\mathrm{OSCA}$ technique (Table 3) showed that the $\mathrm{FAB}+\mathrm{OSCA}$ group had significantly shorter $\mathrm{CPB}$ time and systemic circulatory time, and significantly higher lowest nasopharyngeal temperature $\left(32{ }^{\circ} \mathrm{C}\right)$. Nevertheless, both operative mortality and morbidity of neurological dysfunction had no statistical differences between the two groups, which may be due to the small sample size. Further research with larger sample size is needed to establish the advantages of $\mathrm{FAB}+\mathrm{OSCA}$ as a valuable alternative surgical technique for acute type A aortic dissection patients.

\section{Conclusion}

This study clarified the feasibility of FAB+OSCA technique in modifying Y-graft technique. The acute type A aortic dissection patients showed less surgical complications and favorable short-term outcomes by this surgery. Comparison of the traditional Y-graft technique with the modified Y-graft technique using FAB (Table 2) showed that some indicators were not significantly advanced, but our FAB technique makes the operation easier than before. The reconstruction of the supra-aortic arteries can be accomplished in an unhurried fashion, and the quality of anastomosis can be improved. It also provides a good surgical visual field for distal aortic anastomosis and eases the blood leak sealing.

\section{Abbreviations \\ FAB: Femoral Artery Bypass; OSCA: One Minute Systemic Circulatory Arrest; ACT: Activated Clotting Time}

\section{Acknowledgements}

Not applicable.

\section{Authors' contributions}

Sun Xiangfei and Sun Wenyu conceived and designed the study. Sun Wenyu, Sun Xiangfei, Huo Yufeng, Liu Yimin, Zhao Fen, Du Yonghai, He Songxiong, Liu Chao, Jiang Detian, and Zhou Jinfeng performed the operations. Zhao Qi performed the statistical analysis. Sun Xiangfei wrote the paper. Sun Wenyu reviewed and revised the manuscript. All authors read and approved the manuscript.

\section{Funding}

The study has no funding.

\section{Availability of data and materials}

All data are fully available without restriction.

\section{Ethics approval and consent to participate}

All procedures performed in studies involving human participants were approved by the Ethics Committee of Qilu Hospital of Shandong University. Informed consent was obtained from all individual participants included in the study.

\section{Consent for publication}

All authors have contributed significantly to the content of the article and all authors have read and approve the submission of the manuscript to this journal.

\section{Competing interests}

The authors have declared that no competing interests exists.

\section{Author details}

'Department of Cardiovascular Surgery, Shandong Provincial Hospital, Cheeloo College of Medicine, Shandong University, Jinan, Shandong 250021, China. ${ }^{2}$ Department of Cardiovascular Surgery, Shandong Provincial Hospital Affiliated to Shandong First Medical University, Jinan, Shandong 250021, China. ${ }^{3}$ Department of Gastroenterology, Shandong Provincial Hospital, Cheeloo College of Medicine, Shandong University, Jinan, Shandong 250021, China. ${ }^{4}$ Department of Gastroenterology, Shandong Provincial Hospital Affiliated to Shandong First Medical University, Jinan, Shandong 250021, China. ${ }^{5}$ Department of Cardiovascular Surgery, Qilu Hospital of Shandong University, Qingdao 266011, Shandong, People's Republic of China.

Received: 24 February 2020 Accepted: 12 May 2020

Published online: 20 May 2020

\section{References}

1. LeMaire SA, Price MD, Parenti $J$, Johnson ML, Lay AD, Preventza $O$, et al. Early outcomes after aortic arch replacement by using the Y-graft technique. Ann Thorac Surg. 2011;91:700-7.

2. Spielvogel D, Strauch JT, Minanov OP, Lansman SL, Griepp RB. Aortic arch replacement using a trifurcated graft and selective cerebral antegrade perfusion. Ann Thorac Surg. 2002;74:S1810-4.

3. Spielvogel D, Mathur MN, Lansman SL, Griepp RB. Aortic arch reconstruction using a trifurcated graft. Ann Thorac Surg. 2003;75:1034-6.

4. Strauch JT, Spielvogel D, Lauten A, Galla JD, Lansman SL, McMurtry K, et al. Technical advances in total aortic arch replacement. Ann Thorac Surg. 2004; 77:581-9.

5. Kazui T, Washiyama N, Muhammad BA, Terada H, Yamashita K, Takinami $M$, et al. Total arch replacement using aortic arch branched grafts with the aid of antegrade selective cerebral perfusion. Ann Thorac Surg. 2000;70:3-8.

6. Kazui T, Yamashita K, Washiyama N, Terada H, Bashar AH, Suzuki T, et al. Usefulness of antegrade selective cerebral perfusion during aortic arch operations. Ann Thorac Surg. 2002;74:S1806-9.

7. Spielvogel D, Halstead JC, Meier M, Kadir I, Lansman SL, Shahani R, et al. Aortic arch replacement using a trifurcated graft: simple, versatile, and safe. Ann Thorac Surg. 2005;80:90-5.

8. Spielvogel D, Etz CD, Silovitz D, Lansman SL, Griepp RB. Aortic arch replacement with a trifurcated graft. Ann Thorac Surg. 2007;83:S791-5.

9. Minakawa M, Fukuda I, Yamauchi S, Watanabe K, Kawamura T, Taniguchi S, et al. Early and long-term outcome of total arch replacement using selective cerebral perfusion. Ann Thorac Surg. 2010;90:72-7.

10. Ueda T, Shimizu H, Hashizume K, Koizumi K, Mori M, Shin H, et al. Mortality and morbidity after total arch replacement using a branched arch graft with selective antegrade cerebral perfusion. Ann Thorac Surg. 2003;76:1951-6. 
11. Kazui T, Bashar AH. Aortic arch replacement using a trifurcated graft. Ann Thorac Surg. 2006;81:1552.

12. Bischoff MS, Brenner RM, Scheumann J, Bodian CA, Griepp RB, Lansman SL, et al. Long-term outcome after aortic arch replacement with a trifurcated graft. J Thorac Cardiovasc Surg. 2010;140:571-6.

13. Ouzounian M, LeMaire SA, Coselli JS. Open aortic arch repair: state-of-the-art and future perspectives. Semin Thorac Cardiovasc Surg. 2013;25:107-15.

14. Shelstad RC, Reeves JG, Yamanaka K, Reece TB. Total aortic arch replacement: advantages of varied techniques. Semin Cardiothorac Vasc Anesth. 2016;20:307-13.

\section{Publisher's Note}

Springer Nature remains neutral with regard to jurisdictional claims in published maps and institutional affiliations.

Ready to submit your research? Choose BMC and benefit from:

- fast, convenient online submission

- thorough peer review by experienced researchers in your field

- rapid publication on acceptance

- support for research data, including large and complex data types

- gold Open Access which fosters wider collaboration and increased citations

- maximum visibility for your research: over $100 \mathrm{M}$ website views per year

At BMC, research is always in progress.

Learn more biomedcentral.com/submissions 